\title{
BMJ Open Impact of household shocks on access to healthcare services in Kenya: a propensity score matching analysis
}

\author{
Purity Njagi (D , ${ }^{1}$ Wim Groot, ${ }^{1,2}$ Jelena Arsenijevic ${ }^{3}$
}

To cite: Njagi P, Groot W, Arsenijevic J. Impact of household shocks on access to healthcare services in Kenya: a propensity score matching analysis. BMJ Open 2021;11:e048189. doi:10.1136/ bmjopen-2020-048189

- Prepublication history and additional supplemental material for this paper are available online. To view these files, please visit the journal online (http://dx.doi.org/10.1136/ bmjopen-2020-048189).

Received 18 December 2020 Accepted 13 September 2021

Check for updates

(c) Author(s) (or their employer(s)) 2021. Re-use permitted under CC BY-NC. No commercial re-use. See rights and permissions. Published by BMJ.

${ }^{1}$ Maastricht Graduate School of Governance, UNU-MERIT, Maastricht, The Netherlands ${ }^{2}$ Department of Health Services Research, Maastricht University Faculty of Health Medicine and Life Sciences, Maastricht, The Netherlands

${ }^{3}$ School of Governance, Utrecht University Faculty of Law, Economics and Governance, Utrecht, The Netherlands

Correspondence to

Dr Purity Njagi;

puritynjagih@gmail.com

\section{ABSTRACT}

Objective This study examines the effects of household shocks on access to healthcare services in Kenya. Shocks are adverse events that lead to loss of household income and/or assets.

Design and setting The study used data from the Kenya Integrated Household Budget Survey 2015/2016, a nationally representative cross-sectional survey. A propensity score matching approach was applied for the analysis.

Participants The study sample included 16297 individuals from households that had experienced shocks (intervention) and those that had not experienced shocks (control) within the last 12 months preceding the survey. Outcome measures The outcome of interest was access to healthcare services based on an individual's perceived need for health intervention.

Results The results indicate that shocks reduce access to healthcare services when household members are confronted with an illness. We observed that multiple shocks in a household exacerbate the risk of not accessing healthcare services. Asset shocks had a significant negative effect on access to healthcare services, whereas the effect of income shocks was not statistically significant. This is presumably due to the smoothing out of income shocks through the sale of assets or borrowing. However, considering the time when the shock occurred, we observed mixed results that varied according to the type of shock.

Conclusions The findings suggest that shocks can limit the capacity of households to invest in healthcare services, emphasising their vulnerability to risks and inability to cope with the consequences. These results provoke a debate on the causal pathway of household economic shocks and health-seeking behaviour. The results suggest a need for social protection programmes to integrate mechanisms that enable households to build resilience to shocks. A more viable approach would be to expedite universal health insurance to cushion households from forgoing needed healthcare when confronted with unanticipated risks.

\section{BACKGROUND}

Poor health and the inability to access healthcare are key factors leading to and resulting from poverty. ${ }^{1}$ Although globally, poverty has reduced over time, the majority of the population in developing countries remain poor

\section{Strengths and limitations of this study}

To the best of our knowledge, this is the first study in Kenya that has attempted to examine the impact of negative income and asset shocks on access to healthcare services by household members, using a nationally representative sample.

- The analyses use a propensity score matching approach to construct a quasi-experimental design adjusting for selection bias of households that experienced shocks.

- Shocks in the survey were subjectively defined and self-reported by respondents; thus, they could be biased depending on the respondent's interpretation of asset and income loss.

- Despite the complexities of health-seeking behaviour and the multifaceted nature of shocks, this study assumes a direct interaction between access to healthcare and household shocks to provide estimates of the effects.

- The results provoke the need for a deeper evaluation of the causal pathway of economic shocks on access to healthcare services.

and susceptible to poverty due to natural and economic shocks. ${ }^{2}$ Shocks are defined as adverse events that trigger a decline in well-being, leading to loss of household income, reduction in consumption and loss of productive assets. ${ }^{34}$ They are classified into idiosyncratic shocks, referring to those that affect individuals or households and covariant shocks, referring to those affecting many households, entire communities or regions. ${ }^{5}$

A shock can push an already poor-income household into further poverty or drive a non-poor household below the poverty line. ${ }^{6}$ Households, even those with a relatively higher income, can be disrupted by a financial setback. Financial shocks due to unforeseen expenses and income losses may cause immediate strain, making it difficult to build or rebuild a financial cushion. ${ }^{7}$ More than $60 \%$ of households in sub-Saharan Africa (SSA) are reported to have experienced sudden losses in income and assets. ${ }^{8}$ Due to 
limited formal safety nets such as insurance and social protection in SSA, coping with shocks relies on informal mechanisms such as the sale of assets, reduction of household consumption and borrowing. ${ }^{9}$

In Kenya, the vulnerability of the population to shocks is among the factors that have constrained poverty reduction, ${ }^{10}$ with around $36 \%$ of the population living on less than 134 Kenyan shillings (US\$1.34) per day. ${ }^{11}$ Three in every five households in Kenya have experienced some form of negative shocks with the majority of households reporting a significant rise in food prices, droughts or floods due to extreme weather patterns, death of livestock and death of a family member as severe shocks. These shocks have led to the loss of either income or assets, with a higher incidence in rural areas relative to urban areas. ${ }^{12}$ Severe shocks are reported to cause significant indirect effects on health and disproportionately impact the poorest and most vulnerable. ${ }^{33}$ Negative shocks are shown to have an effect on healthcare for households with limited or no financial protection. ${ }^{14}$ When confronted by economic shocks, households' decisions regarding healthcare use become far more discretionary and complex, given they are faced with dilemmas about spending their limited resources. ${ }^{15}$

This suggests that economic shocks are likely to worsen the risks of forgoing care when needed in high-income and low-income households. Furthermore, even higher income households that are not fully insured against shocks can suffer severe income shortfalls. ${ }^{5}$ In Kenya, for instance, formal mechanisms such as health insurance and access to formal credit that protect households against the financial consequences of shocks are mainly absent, especially among poor rural households. ${ }^{16}$ To date, only about one-fifth of the households in Kenya have some form of health insurance. ${ }^{12}$

The Kenya healthcare system comprises the public system, with major players including the Ministry of Health; and the private sector, including private forprofit, Non-Governmental Organisation (NGO) and Faith-Based Organisation (FBO) facilities. ${ }^{17}$ As of 2013, the healthcare system was decentralised to new subnational units (counties) to improve access and service delivery. ${ }^{18}$ The provision of healthcare in Kenya is financed through government expenditure, out-ofpocket (OOP) expenditure and development partners. ${ }^{19} 20$ OOP expenditures constitute a significant proportion of health funding at $32 \%$ of the total health budget in Kenya. ${ }^{21}$ This spending is due to expenditures at the points of care, which creates financial barriers that threaten the households' financial security. ${ }^{22}$ Health payments that are financed out of existing income may lead some households to poverty while others may forgo treatment due to a lack of financial resources. ${ }^{23}$ By 2013, $6.5 \%$ of Kenyan households experienced catastrophic payments due to healthcare payments, ${ }^{24}$ this incidence has increased to $7.1 \%$ by 2018 with more than 1 million people pushed into poverty due to healthcare payments annually. ${ }^{25}$ Furthermore, $21.4 \%$ of Kenyans report cost as the main barrier preventing them from seeking care when needed. ${ }^{26}$

Nevertheless, there has been an increase in the utilisation of healthcare services in Kenya, although with marked disparities. ${ }^{26}$ Utilisation of healthcare is reported to be higher among rich individuals relative to less well-off, with a significant disparity in preventive and inpatient care, ${ }^{27}$ an indication that economic reasons influence the decision of whether or not to seek healthcare.$^{26}$ Costs of illness can be substantial when people are not financially protected,$^{28}$ and this is further aggravated by shocks. For instance, loss of income has been associated with a higher risk of unmet healthcare needs. ${ }^{29}{ }^{30}$ Affordability is thus an essential element in facilitating entry into the healthcare system and even more so for countries like Kenya where user charges exist. Improved access to the first point of care can reduce the financial burden due to the reduced need for secondary care. ${ }^{31}$ Moreover, delaying treatment when ill may lead to poorer health, thus imposing a larger financial burden on the patient. ${ }^{32}$

While there is substantial literature on the impact of health shocks on household economic outcomes, ${ }^{23} 33-35$ there is limited evidence on how economic shocks interplay with access to healthcare at the household level, particularly in low/middle-income countries. We identified several studies that have assessed the effects of economic crisis at a macro level on healthcare needs ${ }^{3036-38}$; however, most have been conducted in high-income countries. Understanding how financial shocks constrain a household's decisions to seek healthcare is paramount in providing policymakers with the evidence to devise mechanisms that cushion the population from financial risks. Furthermore, many developing countries are challenged with implementing mechanisms that ensure equitable access to effective health interventions and protect their citizens against health and income shocks. ${ }^{39}$ This study explores how shocks affect households' health-seeking behaviour, considering the timing and type of shock. The study, therefore, responds to the question: what is the impact of household shocks on access to healthcare services in Kenya?

\section{METHODS}

\section{Sample data}

The data used for this study were drawn from the 2015/2016 Kenya Integrated Household Budget Survey. This was a nationally representative cross-sectional survey consisting of a sample of 24000 households $(41.2 \%$ in urban and 58.8\% in rural) generated from 2400 clusters (988 in urban and 1412 in rural areas). The survey collected information on key socioeconomic aspects in the country, including general health characteristics. Also, it collected data on covariant and idiosyncratic shocks that negatively impact the households' welfare in Kenya. The information on shocks includes the type of loss to the household, the unit impacted by the shock (household/ community) and how long ago the shock happened. 
The response rate for the study was $90.7 \%$, that is, 21773 households and 92846 household members drawn from 2387 clusters.

Our study data were limited to households that experienced shocks (intervention) and those that had not experienced shocks (control) within the 12 months preceding the survey. This sample included 10232 households from 2387 clusters with 16297 household members who had experienced an illness in the last 4 weeks preceding the survey. The unit of analysis was the individuals within the households.

\section{Measurement}

\section{Outcome variable}

The outcome of interest was 'access to healthcare', which was used as an operational proxy for use. ${ }^{40}$ Access is defined as the timely use of healthcare services which requires gaining entry in the healthcare system where the needed service can be received. ${ }^{41}$ Therefore, our study outcome is limited to the initial point of contact or entry of the individual into the healthcare system. ${ }^{41}$

This variable was derived from the following questions: (1) 'Was (NAME) sick or injured in the last 4weeks?' and (2) 'Did (NAME) consult a health provider on this sickness/injury in the last 4 weeks?' The two questions enabled us to construct the binary variable 'access to healthcare (Yes/No)', which is the decision to demand care based on an individual's perceived need for health intervention.

\section{Treatment variable}

The main independent (treatment) variable of interest was 'shock' derived from the question 'Over the past 5 years, was your household severely affected negatively by any of the following events?' This provided details on the actual type of negative shock experienced by the household, including climate shocks such as floods, loss of crops, loss of livestock, loss of employment or business income, loss of remittances, rise in food prices, crime, fire, ethnic conflict, death and evictions. Health shocks were not included in this study.

The study further analysed the type of impact of the shock as follows: 'Did (THIS SHOCK) cause a reduction in household income and/or assets?' This question refers to the perceived loss by the household as either loss of assets, loss of income, or loss of both income and asset. The focus of this study was shock(s) that were negatively and exclusively associated with income loss, asset loss, or both income and asset loss at the household level.

Data on time in point when the shock happened were equally assessed as 'How long ago did (THIS SHOCK) occur?' This study focused on shocks that occurred within the 12 months preceding the survey. We constructed three time points, including shocks that had occurred exclusively within 7-12 months, 1-6 months and below 1 month. We considered households that experienced only one shock to reduce multiple shocks bias. For instance, a household with multiple shocks may have experienced the shocks at different periods of time, and the shocks may have negatively affected either its assets or income or both. Therefore, we construct multiple treatment groups based on the type of shock and time when the shock occurred within the 12 months.

\section{Matching covariates}

The selection of covariates is a critical aspect in matching as it affects the variance and bias. It is argued that variables related only to the outcome should always be included in a propensity score (PS) model to increase the precision of the exposure effect. ${ }^{42}$ However, given that PSs are intended to reduce confounding, it is recommended to include variables believed to be related to both the treatment and outcome. ${ }^{43} 44$

The variables considered are structured according to the Andersen's healthcare utilisation model, which emphasises that three major components determine service utilisation: need, predisposing and enabling factors. ${ }^{4546}$ These covariates have also been discussed in recent studies as factors influencing healthcare access in Kenya. ${ }^{2732}$ These covariates include the following: the predisposing factors such as 'household head characteristics' (age, gender, education) and 'location of residence', enabling factors such as 'household's economic status', 'household size' and 'health insurance status'. Our dataset was limited in providing the need factors such as chronically ill member and self-rated health status among others. Nevertheless, the outcome variable was based on an individual's perceived need for healthcare.

\section{Analytical approach}

In the absence of a randomised controlled experiment to assess the impact of shocks, we used the potential of observational data and econometric techniques to optimally achieve randomisation. This study used crosssectional data and employed the PS matching (PSM) approach to create a counterfactual to compare the effects between households that have (treatment) and have not (control) experienced a shock. PSM is the conditional probability of assignment to a particular treatment given a vector of observed covariates. ${ }^{47}$ It is an alternative method to estimate the effect of receiving treatment when a random assignment of treatments to subjects is not feasible. ${ }^{48}$ There has been growing interest in the use of PSM to estimate the effects of treatments on outcomes using observational studies. ${ }^{49}$ PSM is argued to correct for selection bias, which is the predominant threat to the validity of using nonexperimental data for impact analyses. ${ }^{50}$

This study implemented PSM by first running a logit model with all the covariates. This estimated the PSs as the probability of experiencing a shock given the confounding factors. The PSs were then used to match individuals from households that experienced a shock and those that did not experience a shock given 
the same likelihood. The outcome of those that experienced shocks was compared with the outcome of a group comparable in observational characteristics but without shocks. This estimated the effect of the shock on access to healthcare services, referred to as average treatment effect on the treated (ATT).

The matching was implemented using the Stata command 'teffects psmatch', which takes into account the fact that PSs are estimated rather than known when calculating SEs. ${ }^{51}$ We estimated the PS using the oneto-one nearest neighbour matching, with a calliper of 0.1 . The 1:1 approach specifies that each individual in the treatment (shocks) is matched with at least one individual from the control (no shocks) level. ${ }^{52}$ The 0.1 calliper specifies the maximum distance for which two observations are potential neighbours. ${ }^{53}$ Studies have recommended using a calliper of a width equal to 0.2 of the SD of the logit of the PS. ${ }^{54}$ It is argued that a tighter calliper can improve the performance of the PSM by reducing the bias further and hence lead to closer matches. ${ }^{55}$ Therefore, a calliper of less than 0.2 , such as in this study, is considered acceptable.

\section{Sensitivity analysis}

For robustness checks of the results, we conducted sensitivity analyses post matching. The checks were run for all the treatment types, including all shocks, multiple shocks, one shock, asset shocks, income shocks, and both asset and income shocks.

Matching is based on the assumption of unconfoundedness; sensitivity analysis is, therefore, useful to assess how robust associations are to potential uncontrolled confounding. ${ }^{56}$ This study used the Mantel-Haenszel (MH) test statistic referred to as 'MH bounds' proposed in several studies for binary outcomes, ${ }^{57}$ to check the sensitivity of the results with respect to deviations from the assumption of unconfoundedness. ${ }^{58} \mathrm{MH}$ bounds were used to test for the conditional independence assumption (hidden bias), which may lead to an overestimation or underestimation of the treatment effect. The MH bound gamma coefficient shows the factor by which the unobserved factors would affect the selection of households with shocks relative to those without shocks but with similar characteristics.

Another assumption was the sufficient overlap in characteristics to ensure adequate matches. Thus, the quality of the PS model should be assessed based on the covariate balance achieved. ${ }^{59}$ To assess the balance of covariates, we used the 'tebalance' command to check the variance after matching. ${ }^{60}$ Similarly, we constructed density plots to observe how the densities for treatment and controls differed before and after matching. The sensitivity analysis results are discussed later in this paper.

\section{Patient and public involvement}

This study used secondary data; therefore, patients were not involved.
RESULTS

\section{Description statistics of the study sample}

Table 1 summarises the study sample characteristics by access to healthcare services within the last 4 weeks preceding the survey. Overall, the eligible sample for this study was 16297 participants, of which those who accessed healthcare services were 13349 (81.9\%), while $2948(18.1 \%)$ did not access healthcare services. Of the sample, $11274(69.2 \%)$ had, and 5023 (30.8\%) had not experienced shocks in the household within the 12 months preceding the survey.

The majority of individuals belonged to male-headed households and were aged between 25 and 40 years. Additionally, the majority of the households had heads with at least primary-level education. We noted that the majority of the sample population were from households above the poverty line and medium-sized households. Lastly, the majority of the study individuals were from uninsured households and resided in rural areas.

Figure 1 below presents the percentage of individuals from households that had experienced shocks in the 12 months preceding the survey. The analysis indicates that $11274(69.2 \%)$ had experienced shocks. Of this, 7320 (44.9\%) had experienced multiple shocks, while 3954 $(24.3 \%)$ had experienced only one shock in the household. Further analyses showed that, of those that had experienced one shock in the household, $1780(45 \%)$ had experienced shocks that led to only income losses, while $550(13.9 \%)$ had experienced shocks that led to only assets losses and $1073(27.1 \%)$ had experienced shocks that led to losses in both income and assets. Another group of 551 (13.9\%) experienced shocks; however, since they reported the shocks not to have affected either assets or income, we have not discussed this group in this study. Online supplemental file 1 provides a further description of the individuals from households that had not experienced any shocks and those from households that had experienced different types of shocks and the time when the shocks occurred.

\section{Effect of shocks on access to healthcare services}

Table 2 presents the mean differences between the households that did and did not experience shocks and the estimated effects of the shocks on the matched samples. After adjusting for systematic differences in the observed characteristics of households with shocks and those without shocks, the results show a significant negative effect of household shocks on access to healthcare services. Generally, shocks contributed to a 1.6 percentage point decrease in access to healthcare services. Multiple shocks reduced access to healthcare services by 2 percentage points.

The assessment of households that experienced only one shock revealed that there was no statistically significant effect on access to healthcare services. Further analysis of these households was carried out by disaggregating them into exclusively asset shocks, income shocks, and both income and asset shocks. Within those that had experienced only one shock, the effect was statistically 
Table 1 Descriptive characteristics of the study sample

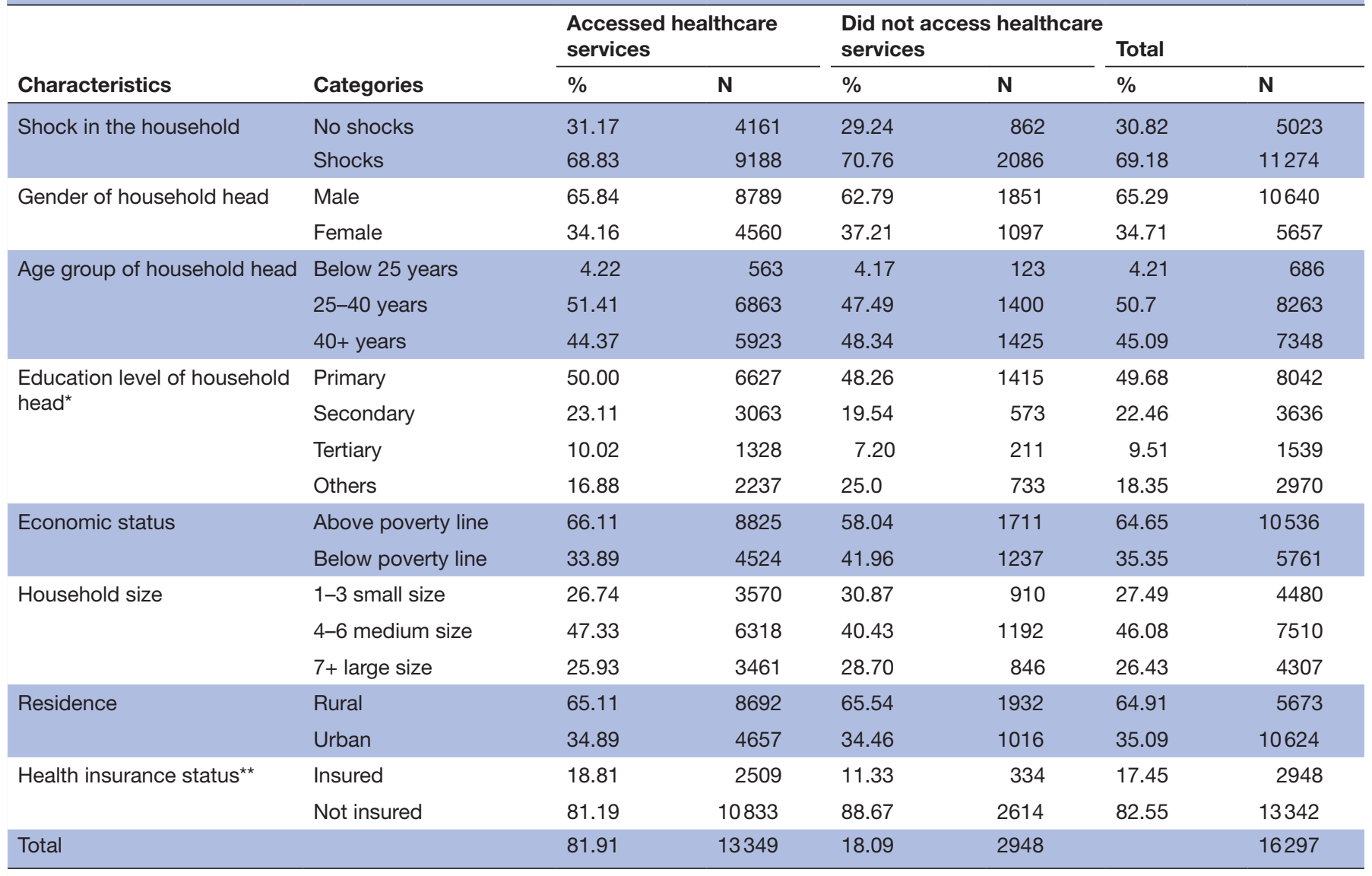

*Don't know, **Missing not included.

significant for only asset shocks. Asset shocks contributed to a 4.1 percentage point decrease in access to healthcare services.

\section{Effect of the type and time of shock on access to healthcare services}

Analysis of the effect by type of shock and the time when the shock occurred is illustrated in table 3 . The findings

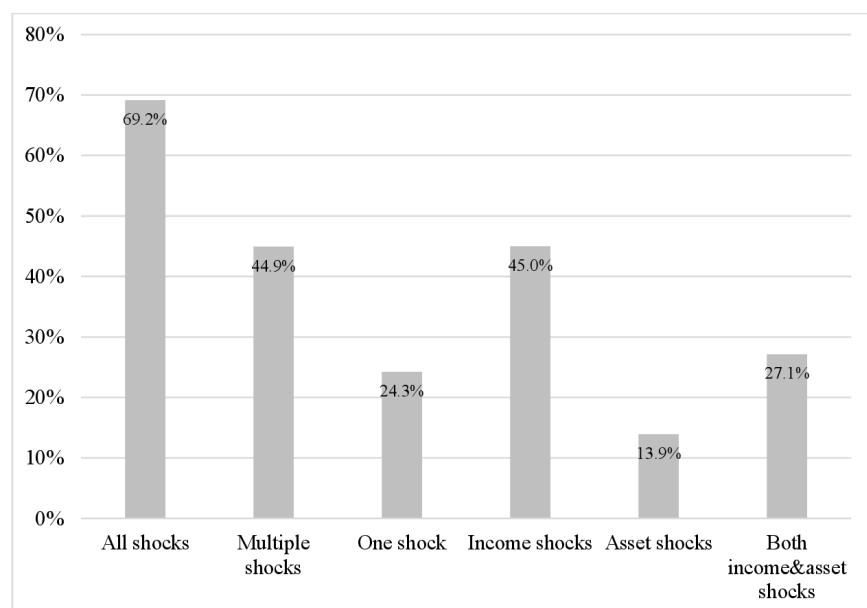

Figure 1 Percentage of individuals from households that had experienced shocks. indicate that there was a significant negative effect on access to healthcare services for asset shocks that occurred between 7 and 12 months. Asset shocks within 7-12 months contributed to a 9.7 percentage point decrease in access to healthcare services. On the contrary, there was a significant positive effect on access to healthcare services for income shocks that had occurred between 1 and 6 months. The results indicate that income shocks within 1-6 months contributed to a 3.5 percentage point increase in access to healthcare services.

Shocks that occurred within less than 1 month happened within the same time illness were reported. A significant negative effect was observed on access to healthcare services for shocks that affected both income and assets in below 1 month. The results indicate a 6.7 percentage point decrease in access to healthcare services for households that experienced both income and asset shocks.

\section{Sensitivity analysis results}

The results of the MH sensitivity analysis are reported in online supplemental file 2. If there is no hidden bias, the gamma coefficient $(\Gamma=1)$ is similar to the ATT estimates. The test statistic (at $\Gamma=1$; the assumption of no hidden bias) for the overall shocks and multiple shocks gave similar results to the ATT estimates suggesting no hidden bias. Checks for the treatment effect by type of 
Table 2 Average treatment effect on the treated (ATT) of shocks on access to healthcare services

\begin{tabular}{|c|c|c|c|c|c|c|c|}
\hline Type of shock & \multicolumn{2}{|c|}{ Means after matching } & \multicolumn{4}{|c|}{ ATT } & $\begin{array}{l}\text { Number of } \\
\text { cases on } \\
\text { support (N) }\end{array}$ \\
\hline All shocks & 0.815 & 0.831 & $-0.016^{\star \star}$ & 0.007 & -2.11 & -0.030 to 0.001 & 16290 \\
\hline One shock & 0.821 & 0.830 & -0.008 & 0.009 & -0.93 & -0.026 to 0.009 & 8972 \\
\hline Asset shocks & 0.785 & 0.827 & $-0.041^{\star *}$ & 0.020 & -2.03 & -0.081 to 0.001 & 5570 \\
\hline $\begin{array}{l}\text { Both asset and income } \\
\text { shocks }\end{array}$ & 0.806 & 0.825 & -0.019 & 0.014 & -1.32 & -0.047 to 0.009 & 6092 \\
\hline
\end{tabular}

${ }^{* * *} \mathrm{P}<0.01,{ }^{* *} \mathrm{p}<0.05$

shocks (one shock, income shocks, assets shocks) indicate varying critical values at $\Gamma=1$, at which the $p$ level of the estimated treatment effect is statistically significant, potentially implying sensitivity to unobserved heterogeneity, which would overestimate the true treatment effect.

Second, the balance between covariate tests shows that matching improved the level of balance given the standardised differences for all covariates categories are close to zero $(0)$, and the variances are close to one (1). The results of the 'tebalance' checks are presented in online supplemental file 3 .

Last, all the density plots show that the matching is balanced between the control and treatment groups as the curves perfectly overlay after matching. Figure 2 below shows the density plots for overall shocks before and after matching. All the density plots for the other treatment(s), that is, the type of shocks and time when the shocks occurred, are presented in online supplemental file 4 .

\section{DISCUSSION}

This study estimated the impact of shocks on the ability to access healthcare services using the PSM approach. The findings show that overall shocks have a significant negative effect on access to healthcare services after matching on all confounding covariates. This is consistent with other studies that have shown that households in economic distress (wealth and income losses) were more likely to reduce medical care usage ${ }^{37}$ Furthermore, in Kenya, the high cost of care and lack of money are reported to be key barriers to accessing healthcare services. ${ }^{32}$ In accordance with other studies elsewhere, ${ }^{61}$ the results show that multiple shocks exacerbate the risk of not accessing healthcare services. Multiple shocks increase the number of adverse welfare outcomes, making recovery and coping much more difficult. ${ }^{61}$ Evidence suggests that consumption smoothing is more challenging with repeated shocks because households may deplete their assets, thus limiting their ability to cope with subsequent shocks; besides, one

Table 3 Average treatment effect on the treated (ATT) by time of shock on access to healthcare services

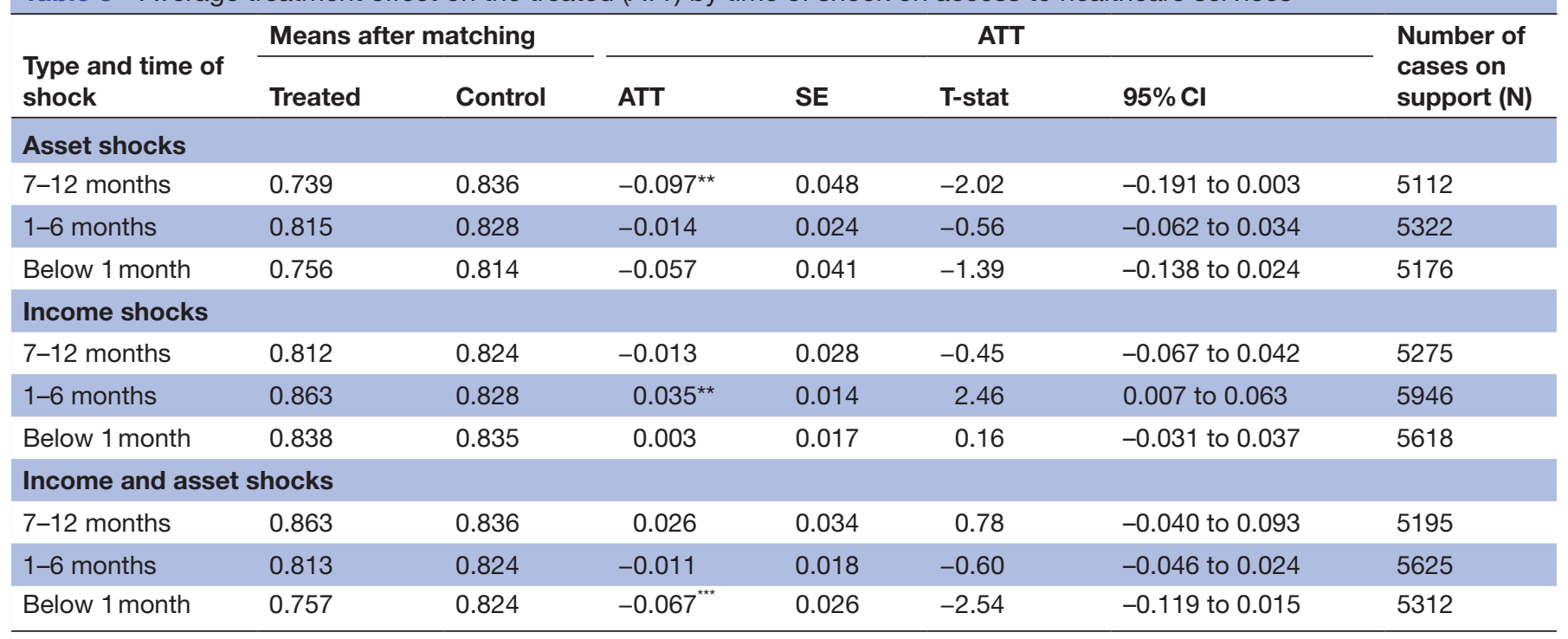

${ }^{* * *} \mathrm{P}<0.01,{ }^{* *} \mathrm{p}<0.05$. 


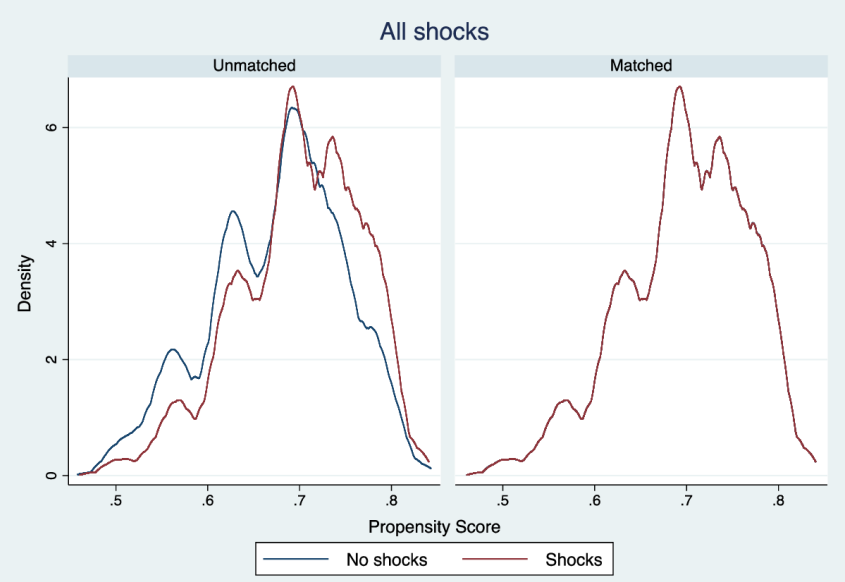

Figure 2 Density plots for all shocks before and after matching.

shock may lead to another. ${ }^{4}$ In Kenya, due to the complex and extreme weather patterns, households are vulnerable to multiple climatic shocks. ${ }^{62}$ Besides, the descriptive analysis indicates that the majority of the households were faced with multiple shocks within the 12 months preceding the survey.

We interpreted the effect results of the type of shocks on access to healthcare services with caution, given the MH bounds' sensitivity checks point to the presence of unobserved heterogeneity, which possibly overestimated the true treatment effect. This insinuates that households that are likely to experience asset and income shocks tend to have lower access rates even in the absence of shocks.

In general, income shocks had no effect on access to healthcare services. However, considering the time when the shock occurred, the results indicate a significant positive effect of income shocks on access to healthcare services in 1-6 months. This could be attributed to the smoothing out of the income shocks by selling assets or borrowing. ${ }^{63}$ In some cases for households with savings, they may prefer to use their savings other than depleting their productive assets to cushion against shocks. ${ }^{64}$ However, evidence shows that savings have a limited role for poor and rural households in SSA. ${ }^{8}$ Other studies corroborate these findings; for example, a study in neighbouring Uganda showed that negative income shocks increased the probability of uptake of healthcare services for children such as the provision of vitamin A supplementation. The buffer stock mechanism was argued to smooth out the shock, allowing for time investment in health promotion for children. ${ }^{14}$ Additionally, income shocks could be transitory, and hence the households may have recovered from the shock at the time of illness. Evidence suggests that households with a relatively high level of assets are not only able to fully offset transitory income shocks, ${ }^{65}$ but also insure against permanent income shocks to some degree. ${ }^{66}$

Overall, households that experienced asset shocks are less likely to access healthcare services when faced with an illness. Considering the time when the asset shocks occurred, the results indicate that a negative effect was observed for asset shocks in 7-12 months. This is perhaps because asset shocks are more permanent; thus, households may take longer to recover. Furthermore, most households consider asset loss to be a more severe shock, and more often in rural areas, the highest percentage of shocks results in asset loss. ${ }^{67}$ Moreover, assets like livestock and farm produce are used as a form of savings and insurance to deal with unexpected expenditures such as medical expenses. ${ }^{68}$ Also, the impact of some of the asset shocks is indirect and not immediate. For instance, the effect of loss of crops due to climatic conditions is experienced in food prices as farmers hoard and store for future sale or consumption. ${ }^{69}$ Since rural populations rely on agricultural produce and livestock to accumulate assets, ${ }^{70}$ asset losses could cause a severe negative impact on the household's welfare. Besides, livestock and crop-related losses have been reported to lead households into poverty in Kenya. ${ }^{72}$ Asset losses pose a significant risk for poor households due to the low level of household asset holding. ${ }^{73}$ Poor households could become locked into a state of few or negligible assets when susceptible to the worst impacts of different types of shocks and thus become stuck in poverty trap. ${ }^{74}$

We note that shocks that led to a loss of both income and assets in below 1 month had a significant negative effect on access to healthcare services. Intuitively, shocks that happen within the time of illness are expected to have a more profound effect on a financially constrained household's decision to seek care. However, given the nature of the data used, we could not establish if the shock happened prior to or after the illness. Furthermore, shocks were subjectively defined by households; hence the value and impact of the shock vary according to the household's economic status. ${ }^{75}$ This suggests that a shock of lower value for a poor household could mean a loss of everything the household owns. In contrast, for well-off households, a high-value loss could be a small proportion of the household wealth, and the household may have alternative assets or savings. This is a reflection of the multifaceted nature of shocks. ${ }^{8}$

Overall, we noted that shocks have an effect on household members' health-seeking behaviours; however, this effect varies according to the timing and type of the shock. Nevertheless, shocks may leave no profound impact on households' economic well-being, given that the adverse impacts of shocks could fade over time due to labour and commodity market adjustments. ${ }^{76}$

In Kenya, climatic shocks happen in tandem with the emergence and spread of some infectious diseases. For instance, during heavy rains that cause floods, diseases such as cholera are bound to spread, whereas during hot weather when droughts occur, diseases such as malaria are prevalent. ${ }^{77}$ This could result in a double burden given the loss of assets or income, which happens simultaneously with the need to access healthcare services, making it arduous for households to cope. 
Kenya has made significant progress in building nationally owned social protection systems. However, these have been targeted at specific population groups, including persons with disabilities, orphans, the elderly and those in food-insecure areas. ${ }^{78}$ Other systems such as the social pension fund and health insurance are voluntary-based on an individual's ability to pay. ${ }^{79}$ This limits coverage for the majority, especially the poor who do not fall into these specified groups. Considering that three out of every five households have experienced a shock, this could mean that thousands of households are at the risk of forgoing the needed healthcare due to risks. Poverty has been reported to have a negative effect on the demand for modern healthcare services in Kenya, in that the poor are less likely to consult a healthcare provider when sick relative to their non-poor counterparts. ${ }^{80}$ Moreover, the majority of the population in Kenya does not possess any form of healthcare insurance.

This study has some limitations that need to be considered while interpreting the findings. First, this study assumes a direct interaction with income and asset shocks to estimate the effects on access to healthcare, yet healthseeking behaviour has a much more complex pathway. Second, we applied PSM, a quasi-experimental approach that removes bias due to observed characteristics but not necessarily the unobserved characteristics. It is, therefore, possible that bias could arise from the variable omission and unobserved heterogeneity. Moreover, panel data are more robust and recommended for this type of impact analysis. Nonetheless, we used all possible observable characteristics evidenced in the literature as confounders and equally ran the sensitivity analysis to check for hidden bias. Third, we used the Kenya household budget survey dataset, which collects a wide range of indicators; hence, it is limited in providing some of the health services data our study could have explored, for instance, need for inpatient versus outpatient services, need factors such as perceived health status and chronic illness within the households. Finally, the access to healthcare services is based on 4 weeks preceding the survey. Therefore, for the shocks that had occurred in below 1 month, we could not discern if they happened prior to or after the illness. Additionally, shocks in the survey were subjectively defined and self-reported depending on the household's interpretation of asset and income losses which may vary.

\section{CONCLUSION}

The adjusted estimates demonstrate that shocks limit the capacity of households to afford and access healthcare services when needed. The effects of shocks on access to healthcare services are dependent on the type of shock and the time when the shock occurred. This fundamentally implies that in countries such as Kenya, where financial protection mechanisms are limited, households adjust their health-seeking behaviour when confronted with resource constraints in times of illness.
The findings provide insights on the vulnerability of households to risks and their inability to cope with the consequences. This should provoke debates on the interaction and causal pathway of the households' economic shocks and health-seeking behaviour. In addition, it calls for the broadening of government social protection programmes to integrate mechanisms that enable households to build resilience to shocks. A more viable approach would be to expedite the expansion of the health insurance scheme(s) to guarantee affordability and accessibility to healthcare services for all.

Contributors PN designed the research methods, conducted the analysis, summarised findings and discussions, constructed the figures and tables, and prepared the draft manuscript. WG and JA provided inputs into the research scope, structure of the manuscript, data analysis and findings, and reviewed all the draft versions of the manuscript. All the authors read and approved the final manuscript.

Funding The authors have not declared a specific grant for this research from any funding agency in the public, commercial or not-for-profit sectors.

Competing interests None declared.

Patient consent for publication Not required.

Provenance and peer review Not commissioned; externally peer reviewed.

Data availability statement Data are available in a public, open access repository. The datasets analysed during the current study are available in the Kenya National Data Archive (KeNADA) repository http://statistics.knbs.or.ke/nada/index.php/ catalog/88.

Supplemental material This content has been supplied by the author(s). It has not been vetted by BMJ Publishing Group Limited (BMJ) and may not have been peer-reviewed. Any opinions or recommendations discussed are solely those of the author(s) and are not endorsed by BMJ. BMJ disclaims all liability and responsibility arising from any reliance placed on the content. Where the content includes any translated material, BMJ does not warrant the accuracy and reliability of the translations (including but not limited to local regulations, clinical guidelines, terminology, drug names and drug dosages), and is not responsible for any error and/or omissions arising from translation and adaptation or otherwise.

Open access This is an open access article distributed in accordance with the Creative Commons Attribution Non Commercial (CC BY-NC 4.0) license, which permits others to distribute, remix, adapt, build upon this work non-commercially, and license their derivative works on different terms, provided the original work is properly cited, appropriate credit is given, any changes made indicated, and the use is non-commercial. See: http://creativecommons.org/licenses/by-nc/4.0/.

ORCID iD

Purity Njagi http://orcid.org/0000-0003-3157-4413

\section{REFERENCES}

1 Gray B, Gash M. Designing financial services to respond to household shocks: a case study of RCPB's health savings and loan product [Internet. Washington, DC: Consultative Group to Assist the Poor(CGAP), 2016. https://www.cgap.org/research/publication/ designing-financial-services-respond-household-shocks

2 World Bank. World Development Report 2014 : Risk and Opportunity-Managing Risk for Development. Washington DC: International Bank for Reconstruction and Development / The World Bank, 2013: 363.

3 Clarke D, Insurance DS. Credit and safety nets for the poor in a world of risk. 18, 2009.

4 World Bank. World development report 2000/2001: attacking poverty [Internet]. Washington, D.C.: World Bank, 2000. Available: http:// documents.worldbank.org/curated/en/230351468332946759/pdf/ 226840WDR00PUB0ng0poverty0200002001.pdf

5 Pradhan KC, Mukherjee S. Covariate and idiosyncratic shocks and coping strategies for poor and Non-poor rural households in India. $J$ Quant Econ 2018;16:101-27.

6 Hoogeveen J, Tesliuc E, Vakis R. A guide to the analysis of risk, vulnerability and vulnerable groups. 41, 2005. 
7 PEW. The role of emergency savings in family financial security. How do families cope with financial shocks? [Internet]. The Pew Charitable Trusts, 2015. Available: https://www.pewtrusts.org/ / media/assets/2015/10/emergency-savings-report-1_artfinal.pdf

8 Nikoloski Z, Christiaensen L, Hill R. Coping with shocks: the realities of African Life. In: Agriculture in Africa: Telling Myths from Facts [Internet]. (Directions in Development - Agriculture and Rural Development). The World Bank, 2017: 123-34. https://elibrary. worldbank.org/doi/abs/10.1596/978-1-4648-1134-0_ch14

9 Heltberg R, Talukdar F, Oviedo AM. Shocks and Coping in SubSaharan Africa:Background paper for the World Development Report 2014 [Internet]. Washington, D.C: The World Bank, 2013. Available: http://surveys.worldbank.org/publications/shocks-and-coping-subsaharan-africa

10 Diwakar V, Shepherd A. A multidimensional analysis. 53, 2018.

11 Chhabra R, Teitelman N, Silver EJ, et al. Vulnerability multiplied: health needs assessment of 13-18-Year-Old female orphan and vulnerable children in Kenya. World Med Health Policy 2018;10:129-45.

12 KNBS. Basic report: based on 2015/16 Kenya integrated household budget survey (KIHBS). Nairobi, Kenya: Kenya National Bureau of Statistics, 2018.

13 Clarke L, Masson VL. Shocks, stresses and universal health coverage: Pathways to address resilience and health [Internet]. Overseas Development Institute, 2017. Available: https://www.odi. org/publications/10993-shocks-stresses-and-universal-healthcoverage-pathways-address-resilience-and-health

14 Baulia S. Is household shock a boon or bane to the utilisation of preventive healthcare for children? Evidence from Uganda [Internet]. Discussion Papers. Aboa Centre for Economicsom, 2018. Available: https://ideas.repec.org/p/tkk/dpaper/dp121.html

15 Monheit A. How does family health care use respond to economic shocks? realized and anticipated effects [Internet]. Massachusetts, Cambridge: National Bureau of Economic Research, 2014. Available: http://www.nber.org/papers/w20348

16 Bonfrer I, Gustafsson-Wright E. Health shocks, coping strategies and foregone healthcare among agricultural households in Kenya. Glob Public Health 2017;12:1369-90.

17 NCAPD, MOH, CBS. Kenya service provision assessment survey 2004. Nairobi, Kenya: National Coordinating Agency for Population and Development, Ministry of Health, Central Bureau of Statistics, and ORC Macro, 2014.

18 Williamson T, Mulaki A. Devolution of Kenya's health system: the role of health Policy project. RTI International, 2015.

19 Chuma J, Maina T, Ataguba J. Does the distribution of health care benefits in Kenya meet the principles of universal coverage? BMC Public Health 2012;12:20.

20 Munge $\mathrm{K}$, Briggs $\mathrm{AH}$. The progressivity of health-care financing in Kenya. Health Policy Plan 2014;29:912-20.

21 David N, Wanjala P. A case for increasing public investments in health. 8, 2020

22 Dutta A, Maina T, Ginivan M, et al. Kenya health financing system assessment, 2018: time to Pick the best path. 118. Washington, DC: alladium, Health Policy Plus, 2018.

23 Amponsah S. The incidence of health shocks, formal health insurance, and informal coping mechanisms. Perspect Global Dev Technol 2016;15:665-95.

24 Njagi P, Arsenijevic J, Groot W. Decomposition of changes in socioeconomic inequalities in catastrophic health expenditure in Kenya. PLoS One 2020;15:e0244428.

25 Salari P, Di Giorgio L, llinca S, et al. The catastrophic and impoverishing effects of out-of-pocket healthcare payments in Kenya, 2018. BMJ Glob Health 2019;4:e001809.

$26 \mathrm{MOH} .2013$ Kenya household health expenditure and utilisation survey. Nairobi, Kenya: Ministry of Health, Kenya, 2014.

27 Ilinca S, Di Giorgio L, Salari P, et al. Socio-Economic inequality and inequity in use of health care services in Kenya: evidence from the fourth Kenya household health expenditure and utilization survey. Int J Equity Health 2019;18:196.

28 WHO. Coping with out-of-pocket health payments: applications of Engel curves and two-part models in six African countries, 2007. Available: http://apps.who.int/iris/handle/10665/85677

29 Cheng T. How income influences our healthcare decisions [Internet]. World Economic Forum, 2015. Available: https://www.weforum. org/agenda/2015/08/how-income-influences-our-healthcaredecisions/

30 Huang J, Birkenmaier J, Kim Y. Job loss and unmet health care needs in the economic recession: different associations by family income. Am J Public Health 2014;104:e178-83.

31 WHO. Building the economic case for primary health care: a scoping review. Geneva, Switzerland: World Health Organisation, 2018.
32 Njagi P, Arsenijevic J, Groot W. Cost-related unmet need for healthcare services in Kenya. BMC Health Serv Res 2020;20:322.

33 Alam K, Mahal A. Economic impacts of health shocks on households in low and middle income countries: a review of the literature. Global Health 2014;10:21.

34 Atake E-H. Health shocks in sub-Saharan Africa: are the poor and uninsured households more vulnerable? Health Econ Rev 2018;8:26.

35 Wagstaff $A$. The economic consequences of health shocks [Internet] The World Bank. (Policy Research Working Papers), 2005. Available: http://elibrary.worldbank.org/doi/book/10.1596/1813-9450-3644

36 Baumbach A, Gulis G. Impact of financial crisis on selected health outcomes in Europe. Eur J Public Health 2014;24:399-403.

37 Lusardi A, Schneider DJ, Tufano P. The economic crisis and medical care usage [Internet]. National Bureau of Economic Research Report No.: 15843, 2010. Available: http://www.nber.org/papers/ w15843

38 Yang BM, Prescott N, Bae EY. The impact of economic crisis on health-care consumption in Korea. Health Policy Plan 2001;16:372-85.

39 Gottret PE, Schieber G. Health financing revisited: a practitioner's guide [Internet]. The World Bank, 2006. Available: https://elibrary. worldbank.org/doi/abs/10.1596/978-0-8213-6585-4

40 Jacobs B, Ir P, Bigdeli M, et al. Addressing access barriers to health services: an analytical framework for selecting appropriate interventions in low-income Asian countries. Health Policy Plan 2012;27:288-300.

41 National academies of sciences $E$, division $H$ and $M$, services $B$ on $\mathrm{HC}$, disabilities $\mathrm{C}$ on $\mathrm{HCU}$ and $\mathrm{A}$ with. factors that affect health-care utilization [Internet]. health-care utilization as a proxy in disability determination. National Academies Press (US), 2018. Available: https://www.ncbi.nlm.nih.gov/books/NBK500097/

42 Brookhart MA, Schneeweiss S, Rothman KJ, et al. Variable selection for propensity score models. Am J Epidemiol 2006;163:1149-56.

43 Garrido MM, Kelley AS, Paris J, et al. Methods for constructing and assessing propensity scores. Health Serv Res 2014;49:1701-20.

44 Caliendo M, Kopeinig S. Some practical guidance for the implementation of propensity score matching. J Econ Surv 2008;22:31-72.

45 Andersen RM. Revisiting the behavioral model and access to medical care: does it matter? J Health Soc Behav 1995;36:1-10.

46 Babitsch B, Gohl D, von Lengerke T. Re-revisiting Andersen's behavioral model of health services use: a systematic review of studies from 1998-2011. Psychosoc Med 2012;9:Doc11.

47 Rosenbaum PR, Rubin DB. The central role of the propensity score in observational studies for causal effects. Biometrika 1983;70:41-55.

48 Thavaneswaran A. Propensity Score Matching in Observational Studies [Internet. Canada: Manitoba Centre for Health Policy, University of Manitoba, 2008. https://www.umanitoba.ca/faculties/ health_sciences/medicine/units/chs/departmental_units/mchp/ protocol/media/propensity_score_matching.pdf

49 Austin PC. An introduction to propensity score methods for reducing the effects of confounding in observational studies. Multivariate Behav Res 2011;46:399-424.

50 Luo Z, Gardiner JC, Bradley CJ. Applying propensity score methods in medical research: pitfalls and prospects. Med Care Res Rev 2010;67:528-54

51 University of Wisconsin. Propensity score matching in stata using teffects [Internet]. supporting statistical analysis for reseacrh, 2015. Available: https://www.ssc.wisc.edu/sscc/pubs/stata psmatch.htm

52 Stuart EA. Matching methods for causal inference: a review and a look forward. Stat Sci 2010;25:1-21.

53 StataCorp. Stata Treatment-Effects Reference Manual: Potential outcomes/counterfactual outcomes:: Release13 [Internet]. StataCorp LLP, 2013. Available: https://www.stata.com/manuals13/ te.pdf

54 Austin PC. Optimal caliper widths for propensity-score matching when estimating differences in means and differences in proportions in observational studies. Pharm Stat 2011;10:150-61.

55 Lunt M. Selecting an appropriate caliper can be essential for achieving good balance with propensity score matching. Am J Epidemiol 2014;179:226-35.

56 VanderWeele TJ, Ding P. Sensitivity analysis in observational research: introducing the E-Value. Ann Intern Med 2017;167:268.

57 Aakvik A. Bounding a matching estimator: the case of a Norwegian training program. Oxf Bull Econ Stat 2001;63:115-43.

58 Becker SO, Caliendo M. Sensitivity analysis for average treatment effects. Stata J 2007;7:71-83.

59 Ali MS, Prieto-Alhambra D, Lopes LC, et al. Propensity score methods in health technology assessment: principles, extended applications, and recent advances. Front Pharmacol 2019;10 https:// www.frontiersin.org/article/10.3389/fphar.2019.00973/full 
60 StataCorp. Stata treatment-effects Reference manual: Potential outcomes/counterfactual outcomes: Release 16 [Internet]. StataCorp LLC, 2019. Available: https://www.stata.com/manuals/te.pdf

61 Mazumdar S, Mazumdar PG, Kanjilal B, et al. Multiple shocks, coping and welfare consequences: natural disasters and health shocks in the Indian Sundarbans. PLoS One 2014;9:e105427.

62 Parry J-E, Echeverria D, Dekens J, et al. Climate risks, vulnerability and governance in Kenya: a review. 83, 2012.

63 McPeak J. Contrasting income shocks with asset shocks: livestock sales in northern Kenya. Oxf Econ Pap 2004;56:263-84 https:// academic.oup.com/oep/article-lookup/doi/10.1093/oep/gpf040

64 Ansah IGK, Gardebroek C, Ihle R. Shock interactions, coping strategy choices and household food security. Clim Dev 2021;13:414-26

65 Beegle K, Dehejia RH, Gatti R. Child labor and agricultural shocks. J Dev Econ 2006;81:80-96.

66 Fella G, Frache S, Koeniger W. Buffer-Stock Saving and Households Response to Income Shocks. SSRN J 2017;102 https://www.ssrn. com/abstract $=2947137$

67 Doss C, Oduro AD, Deere CD. Shocks, assets and social protection: A gendered analysis of Ecuador, Ghana, and Karnataka, India [Internet]. UN Women, 2015. Available: https://www.unwomen.org/ en/digital-library/publications/2015/6/shocks-assets-and-socialprotection

68 Pica-Ciamarra U. Livestock assets, livestock income and rural households, 2011.

69 Sasson A. Food security for Africa: an urgent global challenge. Agric Food Secur 2012;1:2.

70 Bettencourt EMV, Tilman M, Narciso V, et al. The livestock roles in the wellbeing of rural communities of Timor-Leste. Revista de Economia e Sociologia Rural 2015;53:63-80.
71 Rapsomanikis $\mathrm{G}$. The economic lives of smallholder farmers [Internet]. Rome, Italy: Food and Agriculture Organization, 2015. http://www.fao.org/3/a-i5251e.pdf

72 Kristjanson P, Mango N, Krishna A, et al. Understanding poverty dynamics in Kenya. J Int Dev 2010;22:978-96.

73 Endris GS, Kibwika P, Hassan JY, et al. Harnessing social capital for resilience to Livelihood shocks: ethnographic evidence of Indigenous mutual support practices among rural households in eastern Ethiopia. Int J Popul Res 2017;2017:1-26.

74 Mendoza RU, Shocks A. Aggregate shocks, poor households and children: transmission channels and policy responses. SSRN J 2009;5 http://www.ssrn.com/abstract $=1366747$

75 Tran-Quang V. Household behavior and post-shock recovery in Vietnam. 27, 2012.

76 Akter S, Basher SA. The impacts of food price and income shocks on household food security and economic well-being: evidence from rural Bangladesh. Glob Environ Change 2014;25:150-62.

77 National Research Council. Under the weather: climate, ecosystems, and infectious disease [Internet]. Washington, D.C: National Academy Press, 2001. http://site.ebrary.com/id/10038772

78 GOK. Kenya Social Protection Sector Review 2017 report [Internet]. Ministry of Labour and Social Protection, 2017. Available: https:// www.socialprotection.go.ke/wp-content/uploads/2019/10/KENYASOCIAL-PROTECTION-SECTOR-REVIEW-FULL-DOC.pdf

79 Barasa E, Rogo K, Mwaura N, et al. Kenya national Hospital insurance fund reforms: implications and lessons for universal health coverage. Health Syst Reform 2018;4:346-61.

80 Awiti JO. Poverty and health care demand in Kenya. BMC Health Serv Res 2014;14:560. 